\title{
Optimization of Harmony in Team Formation Problem for Sports Clubs: A Real-Life Volleyball Team Application
}

\author{
Gerçek Budak \\ Ankara Y1ldırım Beyazıt University \\ Department of Industrial Engineering \\ Ankara, Turkey \\ İmdat Kara \\ Yusuf Tansel İç \\ Başkent University \\ Department of Industrial Engineering \\ Refail Kasımbeyli \\ Anadolu University \\ Department of Industrial Engineering \\ Turkey
}

\begin{abstract}
Sports team coaches' main concern is forming the best team to win the upcoming match. Even if a team squad is comprised of limited number of players, the combination of them makes out a complicated problem with huge number of possible line-ups and therefore the team coaches necessitate a scientific support on giving the team formation decisions. Academic researches on this subject increase in the last decade since this decision became important financially and solvable as the parameters are reachable. There are many aspects that define the best team such as team harmony, player performance, team strategy, opponent suitability etc. This research proposes a new mathematical model which aims to form the best team with respect to team harmony. The proposed mathematical model supplies a team that the total amount of the satisfactory level of the all assigned players is the highest. Harmony parameters are obtained from players by using questionnaires which consists of the questions of how much is the harmony level with other players and what the best team according to their desire is. A real-life application of the proposed model is displayed on volleyball team formation problem for a team which participates in the men's first division of Turkey in the study as well.
\end{abstract}

Keywords: Team Harmony, Sports, Team Formation Problem, Linear Programming, Volleyball.

\section{Introduction}

Team formation problem for sports clubs is an assignment problem that the team coach tries to form the best team by assigning the players in the squat to the identified positions to win the match (Boon and Sierksma, 2003). The identification of the positions differs one sport branch to other and is made according to the responsibilities and/or locations of the players in the game field (Budak et al., 2017; Ben Abdelkrim et al., 2010). For the decision makers, the most important question to be answered is that "what is the best team".

The best team can be formed with respect to different perspectives which are total performance, team and player harmony, suitability of coach's strategy, opponent team suitability and other dimensions. These perspectives are also affected by uncontrollable factors such as home/away court advantages and disadvantages (Anderson et al., 2012), psychological and physical status of players (Nipper and Smith, 2008), audience affect (Laviers and Sukthankar, 2014) etc.

Team formation problem and player selection has been handled by many academic researchers in last decades since the industrialized sport sector extremely grew financially and international and national player databases are established on player performances. For example, Boon and Sierksma (2003) proposed an assignment based mathematical model which maximizes the assigned players' total performance. 
Özceylan (2016) deployed a case study of the model of Boon and Sierksma (2003) on football team formation by using the data of a football manager computer game. Budak et al. (2017) proposed two new models which extend the Boon and Sierksma's (2003) model in terms of coach's expectation from the players and game strategy. Tavana et al. (2013) assembled a two-phase fuzzy inference system that ranks and selects the alternative players in the first phase and then locates them in-field positions. Dadelo et al. (2014) used Technique for Order Preference by Similarity to Ideal Solution (TOPSIS) to find out the best players by using the data of players' physical measurements. Ahmet et al. (2013) developed a multi-objective genetic algorithm for skills to find out the best team before the season stage on cricket sport. Chen et al. (2014) applied Analytical Hierarchy Process (AHP) and TOPSIS for selecting the best pitcher for the team. There are other researches that support the combination selection and player selection in sports clubs (for further information see Winter et al. (2006), Caro (2012), Villa and Lozano (2016) and Lorains et al. (2013)).

Considering the previous researches and techniques used, this paper develops a new mathematical model for team formation problem of sports clubs. The proposed model considers player preferences that constructs team and player harmony dimension of the team formation problem. This research initializes this consideration in the decision-making process. To achieve this, team harmony is initially quantified by questionnaires to understand player preferences. The player preferences became programmable as it became quantifiable.

In the following section, we output the studies related with team and player harmony and discuss why the harmony concept should be taken under consideration and its implications to the best team. Third section presents the new mathematical formulation by defining its sets, parameters and decision variables and by explaining the constraints and the objective function of it. Forth section deploys a real-life application of the proposed model on a volleyball team which participates in the first division of Men's League of Turkey.

\section{Searching the Best Team: Team and Player Harmony}

Previous studies, generally, explain what is the best team question based upon player performances. The researchers use past player performances, forecasts of future performances or generated subjective evaluations of player performances is being used to form the best teams. The decision makers of the team formation problem should also concern the formed team's harmony. Team harmony and harmony between players have not been considered by previous researches on the team formation problem. This component of the problem affects the players' performance and accordingly it affects the match result (Stevents and Bloom, 2003; Saavedra, 2013).

On the other hand, team harmony issues are studied by several researches such as Yukelson (1997), Murray and Chao (2005), Hinsz et al. (1997), Hutchins (1991) and Levine et al. (1993). Yukelson (1997) output psychological aspects which are common purpose, communication skills, trust and friendship defined the team harmony which. In addition to this, during the season the responsibility and role sharing in the field must be made clearly and effectively (Yukelson, 1997). Murray and Chao (2005) define team harmony as whole of the pairwise relationships with each of the players. A team with excellent relationships with each other skill and emotion wisely creates a harmonic team (Murray and Chao, 2005). Hinsz et al. (1997), Hutchins (1991) and Levine et al. (1993) proposed that the team coordination, responsibility and skill sharing during the game show how the team harmony is.

To recap the topic, team coach's assigned players' satisfaction level based on the role sharing and the preferences on each position summation gives the team harmony level. As these factors are related with the preferences of players, these data can be obtained by applying questionnaires to the players. This questionnaire must contain the questions of "How well you are doing with Player m" and "What is the best team according to you? Form the team that you want to be involved in." The questionnaires should be applied to the players one by one and privately in order not to get corrupted data from the players.

\section{A New Formulation for Team Formation Problem of Sports Clubs}

In this section, a new mathematical model for team formation before the match is introduced. This model considers team and player harmony dimensions of the problem. This proposed mathematical model aims to form the best team by maximizing the total amount of the satisfaction level of the players from the formed team. Coach's strategy is also going to be included in the decision-making process by the constraints of player-position capabilities and skill level thresholds. 
There are three sets in this problem which are player set, position set and skill set. Player set is comprised of the players in the squad which are decided before the season stage and can be shown as

$\mathrm{P}=\{1,2,3 \ldots \mathrm{n}\}$.

Position set is constituted depending on the sport and positions differentiate with each other on responsibilities and location in the field. This set can be found by the handbooks of each team sport branch from the international federations and can be shown as

$\mathrm{R}=\{1,2,3 \ldots \mathrm{m}\}$.

The last set is skills set of the sport and consists of the special movements and activities that typical to the sport branch. These movements and activities are determined according to the necessities of accomplishing the positions' responsibilities. Like the positions set, skill set can be obtained from the handbooks of the sport branch and can be represented as

$\mathrm{S}=\{1,2,3 \ldots \mathrm{k}\}$.

The main parameters of proposed model are importance levels of positions, player-position capabilities, and coach's thresholds on each positions' skills, player gladness among other player and team and players' performance forecasts on each skill for the upcoming match.

Importance levels of position are found by objectively as it depends on many qualitative aspects so that using the experts' opinions is going to avoid subjectivity (Eckenrode, 1965). AHP is one of the best techniques to obtain these weights since the properties of AHP are suitable (Saaty, 1990). There are also other methodologies that could help the decision maker to obtain these parameters such as SMART (Smart Simple Multi Attribute Rating Technique), point allocation, DELPHI method etc. Importance level of $\mathrm{j}^{\text {th }}$ position on the match result is represented as $\mathrm{PR}_{\mathrm{j}}$. They are valued between 0 and 1 and their total for all $\mathrm{j}$ is equal to one.

The parameters that the coach is going to compose according to his/her preferences are player-position capabilities and skill level thresholds. Player-position capabilities parameter is for each player and position and identified by the coach that whether a player can play in that position. This parameter is symbolized as $\mathrm{PP}_{\mathrm{ij}}$. It is valued 1 if the $\mathrm{i}^{\text {th }}$ player is able to play on $\mathrm{j}^{\text {th }}$ position and it is valued 0 for the other case. Thresholds for each position's skill level are identified by the coach according to his/her strategic mentality. This parameter is represented with $\mathrm{HT}_{\mathrm{jy}}$ which shows the minimum expectation of the team coach on $\mathrm{j}^{\text {th }}$ position's $\mathrm{y}^{\text {th }}$ skill and valued between 0 and 100 .

The parameters that the players are going to identify are the gladness level from the other players and gladness from the formed team. Gladness level of a player shows how much a player is glad from the other player and this parameter is valued between 0 and $1 . \mathrm{i}^{\text {th }}$ player's gladness level for $\mathrm{p}^{\text {th }}$ player is shown as $\mathrm{PH}_{\mathrm{ip}}$. Second parameter that players define is team harmony level according to their wish list on other positions. Each player forms a team according to their preferences and this parameter is shown as $\mathrm{TH}_{\mathrm{ipj}}$. If $\mathrm{i}^{\text {th }}$ player assigned $\mathrm{p}^{\text {th }}$ player to the $\mathrm{j}^{\text {th }}$ position the $\mathrm{TH}_{\mathrm{ipj}}$ is equal to 1 and other cases $\mathrm{TH}_{\mathrm{ipj}}$ is valued 0 .

Players' performance forecasts on each skill for the upcoming match are symbolized as $P_{i y}$ which represents the $i^{\text {th }}$ player's $y^{\text {th }}$ skill forecast and they must be valued between $0-100$ as percentage ratios.

The decision variable of team formation problem before the match stage is represented with $\mathrm{x}_{\mathrm{ij}}$ binary variable that shows whether $\mathrm{i}^{\text {th }}$ player is assigned to position $\mathrm{j}$ or not. If $\mathrm{i}^{\text {th }}$ player assigned to $\mathrm{j}^{\text {th }}$ position, $\mathrm{x}_{\mathrm{ij}}$ is equal to 1 and other case it equals to 0 . Another decision variable in this proposed model is $y_{i}$ which is a dependent binary variable that shows if $\mathrm{i}^{\text {th }}$ player is assigned to a position or not. $\mathrm{q}_{\mathrm{ij}}$ is a dependent decision variable that is defined as the gladness level of player $i$ if $i^{\text {th }}$ player is assigned to $j^{\text {th }}$ position. Total team harmony of the players related to positions is defined as a dependent decision variable and symbolized with TM.

The following model is proposed for the team formation problem before the match stage by aiming to maximize the total harmony among the players:

Objective function;

$$
\operatorname{Max} z=\sum_{i}^{m} \sum_{j}^{n} q_{i j} P R_{j}+T M
$$

subject to; 


$$
\begin{aligned}
& \sum_{j=1}^{n} x_{i j} \leq 1, \quad i=1, \ldots, m \\
& \sum_{i=1}^{m} x_{i j}=1, j=1, \ldots, n \\
& \sum_{i}^{m} P_{i y} x_{i j} \geq H T_{j y}, j=1, \ldots, n, y=1, \ldots, k \\
& x_{i j} \leq P P_{i j}, i=1, \ldots, m, j=1, \ldots, n \\
& \sum_{j=1}^{n} x_{i j}=y_{i}, \quad i=1, \ldots, m \\
& \sum_{\substack{p=1 \\
p \neq i}}^{m} P H_{i p} y_{p} x_{i j}=q_{i j}, \quad i=1, \ldots, m, \quad j=1, \ldots, n, \\
& \sum_{i=1}^{m} \sum_{\substack{p=1 \\
p \neq 1}}^{m} \sum_{j}^{n} T H_{i p j} x_{p j}=T M \\
& y_{i,} x_{i j} \in\{0,1\}, i=1, \ldots, m, j=1, \ldots, n(9)
\end{aligned}
$$

Objective function of the proposed model (1) is maximizing the total team harmony. Constraint (2) guarantees that a player could be assigned to one position as a player cannot play in more than one position. There must not be an unassigned position so that constraint (3) establishes each position has an assignment. An assigned player's skill level cannot be less than the thresholds that team coach identified for the assigned position and constraint (4) is added to the model. Constraint (5) provides that the players could only be assigned to the positions that they are capable to play. As defined, $\mathrm{y}_{\mathrm{i}}$ is a dependent decision variable which is obtained with constraint (6). Constraint (8) obtains the total gladness of the players from the formed team position-wisely. Constraint (9) defines the binary decision variables.

Constraint (7) obtains each assigned player's gladness level from the formed team; however, it is structured as non-linear. To use linear programming literature and knowledge this constraint must be linearized for this reason McCormick Envelopment is a useful tool for linearization (McCormick, 1976). By using this technique, constraint (7) is going to be excluded from the model and the following constraints (7a, 7b, 7c and 7d) shown below is going to be included to the mathematical model:

$$
\begin{aligned}
q_{i j} & \geq 0, \quad i=1, \ldots, m, \quad j=1, \ldots, n \\
q_{i j} & \geq \sum_{p}^{m} P H_{i p} x_{i j}+\sum_{p}^{m} P H_{i p} y_{p}-\sum_{p}^{m} P H_{i p}, i=1, \ldots, m, j=1, \ldots, n \\
q_{i j} & \leq \sum_{p}^{m} P H_{i p} x_{i j}, \quad i=1, \ldots, m, \quad j=1, \ldots, n \\
q_{i j} & \leq \sum_{p}^{m} P H_{i p} y_{p}, \quad i=1, \ldots, m, \quad j=1, \ldots, n
\end{aligned}
$$

The total number of decision variables in this mathematical model is $\left(2 m n+n\left(m^{2}-m\right)+2 m+1\right)$ and total number of constraints is $(6 m n+n k+2 m+n+3)$. Therefore, assuming $m \geq n$ and $m \geq k$ the model greatness is $\mathrm{O}\left(\mathrm{m}^{3}\right)$.

A real-life application is going to be demonstrated in the next section for the volleyball team formation problem before the match stage to show how the model components could be founded out, model solving and interpretation of the result should be made. 


\section{A Real-Life Volleyball Application}

A real-life application for team formation problem before the match stage is exemplified with a first division volleyball team in Turkey for forming the lineup at a season game. In this section, the sets and main parameters are going to be found out and model outputs are obtained.

The player set consists of the players that are in the squad which is 14 players. The position set and skill set for volleyball sport could be found out from the volleyball handbook of international federation. According to the handbook, it is defined that there are 7 positions which are Setter (S), Libero (L), Middle Blocker 1 (M1), Middle Blocker 2 (M2), Side Player 1 (SP1), Side Player 2 (SP2) and Opposite Player (O) (Toyoda, 2011). Skill set has 5 skills which are listed as Serve (SE), Reception (R), Block (B), Attack (A) and Pass (P) (Toyoda, 2011).

Importance of the positions parameter is obtained by using AHP results of Budak et al (2017). The attendees of the process are 20 experts of volleyball sport. AHP is applied to these experts by questionnaires of pairwise comparisons using Saaty's 1-9 scale (Saaty, 1990). The experts' judgements with consistent weights are averaged geometrically and shown in Appendix 1.

The parameters that refer the team coach's preferences are determined by using questionnaires to the team coach. Player-position capabilities and skill level thresholds are identified by questionnaire to the coach and the coach relates these questions with the strategy of the upcoming match. The coach determined parameters are shown in Appendix 2.

Player preferences are related with the harmony between each other and positional gladness of the other assigned players. These data are obtained by questionnaires to all 14 players by asking their level of gladness with each player and the team they want to play. These parameters are demonstrated in Appendix 3.

Forecasts of players' performances on each skill are made with their past performances by using three period moving averages as shown in Appendix 4.

The parameters that found out are implemented to proposed mathematical model and solved by solved by using CPLEX interactive optimizer version 12.6.0.0 on a simple laptop with 8GB RAM Intel® Core ${ }^{\mathrm{TM}}$ i7-3537U CPU at $2 \mathrm{GHz} 64$ byte system. The formed team is given below:

Table 1: Result of the Proposed Model

\begin{tabular}{|l|l|l|l|l|l|l|l|}
\hline Positions & S & L & MB1 & MB2 & SP1 & SP2 & O \\
\hline Assigned Players & 14 & 3 & 7 & 10 & 6 & 9 & 8 \\
\hline
\end{tabular}

As shown in Table 1, the assignments are made as player 14 to setter position, player 3 to libero position, player 7 and 10 to middle blocker positions, player 6 and 9 to side player positions and player 8 to opposite position. The objective function of the proposed model is equal to 82.84 . The team with a perfect harmony could possible make the objective function of the proposed model equal to 130 for this application.

The formed team is the best team that is to be formed possibly. The assigned players are suitable to the thresholds, suitable to the possible positions of the players and have the highest harmony between them. It can be easily observed that from the $\mathrm{PH}_{\mathrm{ip}}$ and $\mathrm{TH}_{\mathrm{ipj}}$ parameters of the assigned players from the Appendix3, these players get along with the other players highly according to the other players' declarations.

\section{Conclusions}

Team formation problem for the sports clubs before the match stage is a crucial problem for the team coaches both financially and to be successful. This problem and solution approach in the previous researches has been observed and it is shown that the need for a harmony based approach is essential.

This paper achieves the quantification of the team harmony concept by considering the psychological aspects of team players. Team harmony is defined as the players' preference in field and positions. By assuming this definition, player's performances are dependent on the team harmony expression is regarded.

This paper initializes a novel approach to solve the team formation problems with a harmony based mathematical model which also integrates the coach's strategy, mentality and expectations to the decision process. This model is a useful tool for the team coaches to observe the team with the best harmony which is over the thresholds determined by the team coach. 
This paper invites statistics, sports and forecast scientist to make a broader research on player performance predictors for the upcoming matches, seasons. As this parameter is forecasted more sensitively, this model outputs will be more realistic. This model also can be improved since it is a general model for all sport branches. The model can be evolved and applications and case studies could be made to different sport branches as well. Nonetheless, different quantification techniques might be used for the measurement of the harmony among the players.

\section{References}

Abdelkrim, N. B., Chaouachi, A., Chamari, K., Chtara, M., \& Castagna, C. (2010). Positional role and competitive-level differences in elite-level men's basketball players. The Journal of Strength \& Conditioning Research, 24(5), 1346-1355.

Ahmed, F., Deb, K., \& Jindal, A. (2013). Multi-objective optimization and decision making approaches to cricket team selection. Applied Soft Computing, 13(1), 402-414.

Anderson, M., Wolfson, S., Neave, N., \& Moss, M. (2012). Perspectives on the home advantage: A comparison of football players, fans and referees. Psychology of Sport and Exercise, 13(3), 311-316.

Boon, B. H., \& Sierksma, G. (2003). Team formation: Matching quality supply and quality demand. European Journal of Operational Research, 148(2), 277-292.

Budak, G., KARA, İ., \& İÇ, Y. T., (2017). Weighting the Positions and Skills of Volleyball Sport by Using AHP: A real life application. IOSR Journal of Sports and Physical Education, 4(1), 23-29.

Budak, G., Kara, İ., İç, Y. T., \& Kasımbeyli, R. (2017). New mathematical models for team formation of sports clubs before the match. Central European Journal of Operations Research, 1-17.

Caro, C. A. (2012). College football success: The relationship between recruiting and winning. International Journal of Sports Science \& Coaching, 7(1), 139-152.

Chen, C. C., Lee, Y. T., \& Tsai, C. M. (2014). Professional baseball team starting pitcher selection using AHP and TOPSIS methods. International Journal of Performance Analysis in Sport, 14(2), 545-563.

Dadelo, S., Turskis, Z., Zavadskas, E. K., \& Dadeliene, R. (2014). Multi-criteria assessment and ranking system of sport team formation based on objective-measured values of criteria set. Expert Systems with Applications, 41(14), 6106-6113.

Eckenrode, R. T. (1965). Weighting multiple criteria. Management science, 12(3), 180-192.

Hinsz, V. B., Tindale, R. S., \& Vollrath, D. A. (1997). The emerging conceptualization of groups as information processors. Psychological bulletin, 121(1), 43.

Hutchins, E. (1991). The social organization of distributed cognition. L. B. Resnick, J. M. Levine, and S. D. Teasley (Eds.), Perspectives on socially shared cognition, pp. 283-307. Washington, DC: APA.

Levine, J. M., Resnick, L. B., \& Higgins, E. T. (1993). Social foundations of cognition. Annual review of psychology, 44(1), 585-612.

Laviers, K. R. \& Sukthankar, G. (2014), Chapter 13 - Using Opponent Modeling to Adapt Team Play in American Football. Plan, Activity, and Intent Recognition, Boston, pp. 313-341.

Lorains, M., Ball, K., \& MacMahon, C. (2013). Performance analysis for decision making in team sports. International Journal of Performance Analysis in Sport, 13(1), 110-119.

McCormick G.P. (1976). Computability of global solutions to factorable nonconvex programs: part I convex underestimatıng problems. Mathematical Programming 10, 147-175, North-Holland Publishing Company.

Murray, J. Y., \& Chao, M. C. (2005). A cross-team framework of international knowledge acquisition on new product development capabilities and new product market performance. Journal of International Marketing, 13(3), 54-78.

Nippert, A. H., \& Smith, A. M. (2008). Psychologic stress related to injury and impact on sport performance. Physical medicine and rehabilitation clinics of North America, 19(2), 399-418.

Ozceylan, E. (2016). A mathematical model using AHP priorities for soccer player selection: a case study. South African Journal of Industrial Engineering, 27(2), 190-205.

Saaty, T. L. (1990). Decision making for leaders: the analytic hierarchy process for decisions in a complex world. RWS publications.

Saavedra, L. K. (2013). Effective team building: The role of coaches. Strategies, 26(4), 3-6. 

43-54.

Stevents, D., \& Bloom, G. (2003). The effect of team building on cohesion. AVANTE-ONTARIO-, 9(2),

Tavana, M., Azizi, F., Azizi, F., \& Behzadian, M. (2013). A fuzzy inference system with application to player selection and team formation in multi-player sports. Sport Management Review, 16(1), 97-110.

Toyoda H. (2011). Coaches Manual I: Chapter V-Volleyball for beginners. Fédération Internationale de Volleyball, e-book.

Villa, G., \& Lozano, S. (2016). Assessing the scoring efficiency of a football match. European Journal of Operational Research, 255(2), 559-569.

Winter, E. M., Jones, A. M., Davison, R. R., Bromley, P. D., \& Mercer, T. H. (Eds.). (2006). Sport and Exercise Physiology Testing Guidelines: Volume I-Sport Testing: The British Association of Sport and Exercise Sciences Guide. Routledge.

Yukelson, D. (1997). Principles of effective team building interventions in sport: A direct services approach at Penn State University. Journal of Applied Sport Psychology, 9(1), 73-96.

\section{Appendix 1: Importance of the Positions $\left(\mathbf{P R}_{\mathbf{j}}\right)$}

\begin{tabular}{|l|l|l|l|l|l|l|l|l|}
\hline Positions & S & L & MB1 & MB2 & SP1 & SP2 & O & Total \\
\hline Weights & 0.26 & 0.07 & 0.12 & 0.12 & 0.13 & 0.13 & 0.18 & 1.00 \\
\hline
\end{tabular}

\section{Appendix 2: Coach's Preferences $\left(\mathrm{PP}_{\mathrm{ij}}\right.$ and $\left.\mathrm{HT}_{\mathrm{jy}}\right)$}

\begin{tabular}{|l|l|l|l|l|l|l|l|}
\hline Players/Positions & S & L & MB1 & MB2 & SP1 & SP2 & O \\
\hline Player 1 & 0 & 0 & 1 & 1 & 0 & 0 & 0 \\
\hline Player 2 & 1 & 0 & 0 & 0 & 0 & 0 & 0 \\
\hline Player 3 & 0 & 1 & 0 & 0 & 0 & 0 & 0 \\
\hline Player 4 & 0 & 0 & 1 & 1 & 0 & 0 & 0 \\
\hline Player 5 & 0 & 0 & 0 & 0 & 1 & 1 & 1 \\
\hline Player 6 & 0 & 0 & 0 & 0 & 1 & 1 & 0 \\
\hline Player 7 & 0 & 0 & 1 & 1 & 0 & 0 & 0 \\
\hline Player 8 & 0 & 0 & 0 & 0 & 0 & 0 & 1 \\
\hline Player 9 & 0 & 0 & 0 & 0 & 1 & 1 & 0 \\
\hline Player 10 & 0 & 0 & 1 & 1 & 0 & 0 & 1 \\
\hline Player 11 & 0 & 0 & 1 & 1 & 0 & 0 & 0 \\
\hline Player 12 & 0 & 0 & 0 & 0 & 1 & 1 & 1 \\
\hline Player 13 & 0 & 1 & 0 & 0 & 0 & 0 & 0 \\
\hline Player 14 & 1 & 0 & 0 & 0 & 0 & 0 & 0 \\
\hline
\end{tabular}

\begin{tabular}{|l|l|l|l|l|l|l|l|}
\hline Skills/Positions & S & L & MB1 & MB2 & SP1 & SP2 & O \\
\hline Serve & 35 & 0 & 20 & 20 & 20 & 20 & 20 \\
\hline Reception & 0 & 10 & 0 & 0 & 20 & 20 & 0 \\
\hline Block & 10 & 0 & 20 & 20 & 20 & 20 & 20 \\
\hline Attack & 0 & 0 & 25 & 25 & 20 & 20 & 40 \\
\hline Pass & 40 & 0 & 0 & 0 & 0 & 0 & 0 \\
\hline
\end{tabular}


Appendix 3: Player's Preferences $\left(\mathrm{PH}_{\mathrm{ip}}\right.$ and $\left.\mathbf{T H}_{\mathrm{ipj}}\right)$

\begin{tabular}{|l|l|l|l|l|l|l|l|l|l|l|l|l|l|l|}
\hline Players & $\mathbf{1}$ & $\mathbf{2}$ & $\mathbf{3}$ & $\mathbf{4}$ & $\mathbf{5}$ & $\mathbf{6}$ & $\mathbf{7}$ & $\mathbf{8}$ & $\mathbf{9}$ & $\mathbf{1 0}$ & $\mathbf{1 1}$ & $\mathbf{1 2}$ & $\mathbf{1 3}$ & $\mathbf{1 4}$ \\
\hline Player 1 & 0 & 2 & 4 & 4 & 5 & 1 & 5 & 3 & 5 & 2 & 3 & 4 & 5 & 5 \\
\hline Player 2 & 1 & 0 & 3 & 1 & 3 & 5 & 3 & 5 & 5 & 5 & 3 & 1 & 3 & 1 \\
\hline Player 3 & 5 & 2 & 0 & 5 & 5 & 3 & 5 & 2 & 3 & 3 & 5 & 5 & 5 & 5 \\
\hline Player 4 & 5 & 5 & 5 & 0 & 5 & 5 & 5 & 5 & 5 & 5 & 5 & 5 & 5 & 5 \\
\hline Player 5 & 5 & 3 & 5 & 5 & 0 & 4 & 5 & 1 & 5 & 4 & 5 & 5 & 5 & 5 \\
\hline Player 6 & 1 & 5 & 1 & 1 & 1 & 0 & 4 & 5 & 5 & 5 & 3 & 5 & 5 & 3 \\
\hline Player 7 & 3 & 1 & 5 & 4 & 5 & 1 & 0 & 1 & 1 & 1 & 5 & 5 & 4 & 5 \\
\hline Player 8 & 5 & 4 & 4 & 5 & 5 & 4 & 4 & 0 & 5 & 5 & 5 & 4 & 5 & 5 \\
\hline Player 9 & 2 & 5 & 4 & 5 & 4 & 5 & 5 & 5 & 0 & 5 & 2 & 2 & 5 & 4 \\
\hline Player 10 & 1 & 5 & 3 & 2 & 4 & 4 & 5 & 1 & 5 & 0 & 1 & 3 & 4 & 2 \\
\hline Player 11 & 1 & 2 & 4 & 1 & 5 & 3 & 1 & 3 & 3 & 3 & 0 & 5 & 5 & 5 \\
\hline Player 12 & 5 & 4 & 5 & 5 & 5 & 4 & 5 & 5 & 5 & 4 & 5 & 0 & 4 & 5 \\
\hline Player 13 & 5 & 4 & 1 & 5 & 5 & 4 & 5 & 4 & 4 & 4 & 5 & 5 & 0 & 5 \\
\hline Player 14 & 5 & 5 & 5 & 5 & 5 & 5 & 5 & 5 & 5 & 5 & 5 & 5 & 5 & 0 \\
\hline
\end{tabular}

\begin{tabular}{|l|l|l|l|l|l|}
\hline Players/Positions & S & L & MB1-MB2 & SP1-SP2 & O \\
\hline Player 1 & 14 & 13 & $1-7$ & $5-9$ & 8 \\
\hline Player 2 & 2 & 3 & $7-10$ & $6-9$ & 5 \\
\hline Player 3 & 14 & 3 & $7-11$ & $6-9$ & 5 \\
\hline Player 4 & 14 & 3 & $4-7$ & $6-9$ & 5 \\
\hline Player 5 & 14 & 3 & $7-11$ & $5-9$ & 10 \\
\hline Player 6 & 2 & 13 & $7-11$ & $6-9$ & 10 \\
\hline Player 7 & 14 & 3 & $7-11$ & $5-9$ & 12 \\
\hline Player 8 & 14 & 13 & $7-10$ & $6-9$ & 8 \\
\hline Player 9 & 2 & 13 & $7-10$ & $6-9$ & 8 \\
\hline Player 10 & 2 & 3 & $4-7$ & $6-9$ & 10 \\
\hline Player 11 & 14 & 13 & $7-11$ & $5-9$ & 8 \\
\hline Player 12 & 14 & 3 & $4-7$ & $5-9$ & 12 \\
\hline Player 13 & 14 & 13 & $4-7$ & $5-9$ & 8 \\
\hline Player 14 & 14 & 3 & $7-10$ & $6-9$ & 8 \\
\hline
\end{tabular}

Appendix 4: Forecasts of players' performances on each skill $\left(P_{i y}\right)$

\begin{tabular}{|l|l|l|l|l|l|}
\hline Player/Skills & Serve & Reception & Block & Attack & Pass \\
\hline Player 1 & 50.0 & 0.0 & 33.3 & 25.0 & 0.0 \\
\hline Player 2 & 50.0 & 16.7 & 8.3 & 58.3 & 42.8 \\
\hline Player 3 & 0.0 & 66.8 & 0.0 & 0.0 & 0.0 \\
\hline Player 4 & 52.4 & 33.3 & 11.0 & 90.3 & 0.0 \\
\hline Player 5 & 31.3 & 33.3 & 33.3 & 65.2 & 0.0 \\
\hline Player 6 & 23.6 & 30.3 & 24.3 & 74.2 & 0.0 \\
\hline Player 7 & 42.6 & 33.3 & 37.7 & 72.2 & 0.0 \\
\hline Player 8 & 41.2 & 0.0 & 33.0 & 72.7 & 0.0 \\
\hline Player 9 & 40.4 & 60.3 & 35.3 & 69.5 & 0.0 \\
\hline Player 10 & 46.5 & 0.0 & 35.7 & 79.0 & 0.0 \\
\hline Player 11 & 50.3 & 0.0 & 55.7 & 87.3 & 0.0 \\
\hline Player 12 & 16.7 & 0.0 & 11.0 & 26.7 & 0.0 \\
\hline Player 13 & 0.0 & 16.7 & 0.0 & 4.2 & 0.0 \\
\hline Player 14 & 45.0 & 0.0 & 20.0 & 0.0 & 48.0 \\
\hline
\end{tabular}

